\title{
The Focus and Trend of STEM Education Research in China-Visual Analysis Based on CiteSpace
}

\author{
Chendong Zhou, Yuanyuan $\mathrm{Li}^{*}$ \\ School of Education and Science, Nanjing Normal University, Nanjing, China \\ Email: *1335605348@qq.com
}

How to cite this paper: Zhou, C. D., \& $\mathrm{Li}$, Y. Y. (2021). The Focus and Trend of STEM Education Research in China-Visual Analysis Based on CiteSpace. Open Journal of Social Sciences, 9, 168-180. https://doi.org/10.4236/jss.2021.97011

Received: June 6, 2021

Accepted: July 16, 2021

Published: July 19, 2021

Copyright ( 2021 by author(s) and Scientific Research Publishing Inc. This work is licensed under the Creative Commons Attribution International License (CC BY 4.0).

http://creativecommons.org/licenses/by/4.0/

\begin{abstract}
In this study, 1146 journal papers on Chinese STEM education research were visualized by using CiteSpace visualization software. It is found that the core group of authors of STEM education research in China has not been formed. Also, there is no universal cooperation among the research institutions. The core areas of research include STEM education abroad, analysis of STEM theory, STEM curriculum and teaching. China's STEM education research can be roughly divided into three periods: initial exploration period, rapid development period and deepening research period. The key areas of future research are science education, research on foreign STEM education and modern educational technology innovation.
\end{abstract}

\section{Keywords}

STEM Education, Research Hotspot, CiteSpace, Visual Analysis

\section{Introduction}

STEM education is the English acronym of Science, Technology, Engineering and Mathematics education. The United States is the first country to put forward the idea of STEM. As early as 1986, the United States began to study STEM education. On the official website of STEM education center of Valley City State University in the United States, it explains what STEM education is, "STEM education goes far beyond its acronym. It is not only science, technology, engineering and mathematics, but also a kind of project-based learning about students' participation. It uses the process of scientific inquiry and engineering design. It is an active interdisciplinary learning. It solves real situation problems through cooperation and integrates learning process and knowledge content" 
(Zhao, 2015). After the introduction of STEM education into China, domestic scholars have also made a localization definition of STEM education. Qin and Fu (2017) believe that the essence of STEM education is to cultivate STEM literacy as the goal, and carry out interdisciplinary education based on real problem scenarios. From the perspective of learning stage, STEM education covers the education range from $\mathrm{K}-12$, undergraduate to graduate stage, which represents a kind of cultural literacy of engineering thinking, and promotes students' deep learning, inquiry learning and meaning learning. Subsequently, the theoretical research and practical research on STEM education gradually increased. In theory, $\mathrm{Yu}$ and $\mathrm{Hu}$ (2015) elaborated nine core concepts of STEM education, which are interdisciplinary, interesting, experiential, situational, collaborative, design, artistic, empirical, and technological enhancement. This paper introduces two interdisciplinary integration modes of related courses and wide area courses, analyzes three interdisciplinary integration orientations: subject knowledge integration orientation, life experience integration orientation and learner centered integration orientation, and puts forward the project design mode of interdisciplinary integration. Zhu and Lei (2017) summed up and analyzed the main practice models of stem education in the world from the perspectives of national education concept and policy orientation, implementation strategy, curriculum construction, teaching exploration and stem ecological development. This paper puts forward some suggestions on the four-layer structure, integration mechanism, discipline construction methodology, capacity building and learning ecosystem development of stem education in China. In practice, Ye and Zhu (2016) took the elevator as an example, and combined with the actual situation of Chinese middle schools, developed STEM curriculum with local characteristics. Based on the case study of STEM curriculum in the d.loft STEM learning project of Stanford University School of Education and School of Design, Chen and Tian (2019) construct an interdisciplinary STEM curriculum model based on design thinking, and puts forward relevant implementation suggestions, so as to provide valuable reference for the practice of STEM education in China. With the deepening of STEM education research in China, the Chinese government has gradually attached importance to STEM education. In June 2017, the Chinese Academy of Educational Sciences held the inaugural meeting of STEM Education Research Center, officially released the white paper on STEM education in China, and launched the "China STEM 2029 innovation action plan". Based on the background and current situation of STEM education in China, this paper points out the connotation of STEM education with Chinese characteristics, and points out the direction for the development of STEM education in China in the next few years. Under the influence of national policies and new education concepts, STEM education is growing in China, and its research scope is becoming wider and wider.

In this context, this study uses CiteSpace 5.2 visual analysis tool to analyze STEM education literature in China. Through the analysis of the research authors, research institutions, key words and research trends of STEM education in 
China, this paper shows the development of STEM education in China, grasps the main direction of STEM education research in China, and provides effective reference for the development of STEM education in China in the future.

\section{Research Design}

\subsection{Research Tools}

CiteSpace is a visual citation analysis software developed in the context of scientometrics, Data and information visualization that looks at the underlying knowledge of analytical scientific analysis (Li \& Chen, 2016). The functions of CiteSpace software are Keyword, Cited Author, Cited Journal, Cited Reference, Keyword emergence and so on. Through these functions, China's STEM education development process, hot trends and future trends can be more completely displayed.

\subsection{Data Source}

The data used in this study are from China national knowledge infrastructure (CNKI), which is the most authoritative search platform for academic papers in China. Based on the advanced search function of CNKI, the paper searched for "STEM education" as "Subject", and selected the catalogue of "Social Sciences II". A total of 1179 journal articles were retrieved in the 2021 of April. After screening and rejecting the invalid literature, a total of 1146 literature data were obtained. The first paper on Chinese STEM education was published in 2008. After importing the results into CiteSpace, a visual analysis of the 1146 papers was performed using a time span of 2008 to 2021 and a time slice of 1 year.

\section{Data Analysis and Results}

\subsection{Bibliometrics Analysis of STEM Education Research in China}

\subsubsection{Analysis by Study Authors}

The core author is a researcher who plays a leading role in this research field. The research subject and trend reveal the research emphasis and trend in this field (Han, 2018). The determination of the core authors of Chinese STEM education research is beneficial to the later researchers' understanding and grasp of the research results in the field of STEM education and provides reference for further research. According to Place's core author formula $M=0.749\left(N_{\max }\right)^{1 / 2}, M$ is the number of papers, NMAX is the number of papers of the most productive authors in the statistical period, and the authors who publish more than $M$ papers are the core authors in this field (Price \& Zhang, 1984). The statistical result of citespace is shown in Figure 1, the author with the highest output of papers is Huichen Zhao, the author with 17 papers published gets $N_{\max }=17$, and the author with more than 3 papers published gets $M=3.08$. According to statistics, China's STEM education research core author a total of 55, the core author of 284 articles, accounting for $24.8 \%$ of the total literature, did not meet the $50 \%$ target proposed by Place. This indicates that the core author group of Chinese 


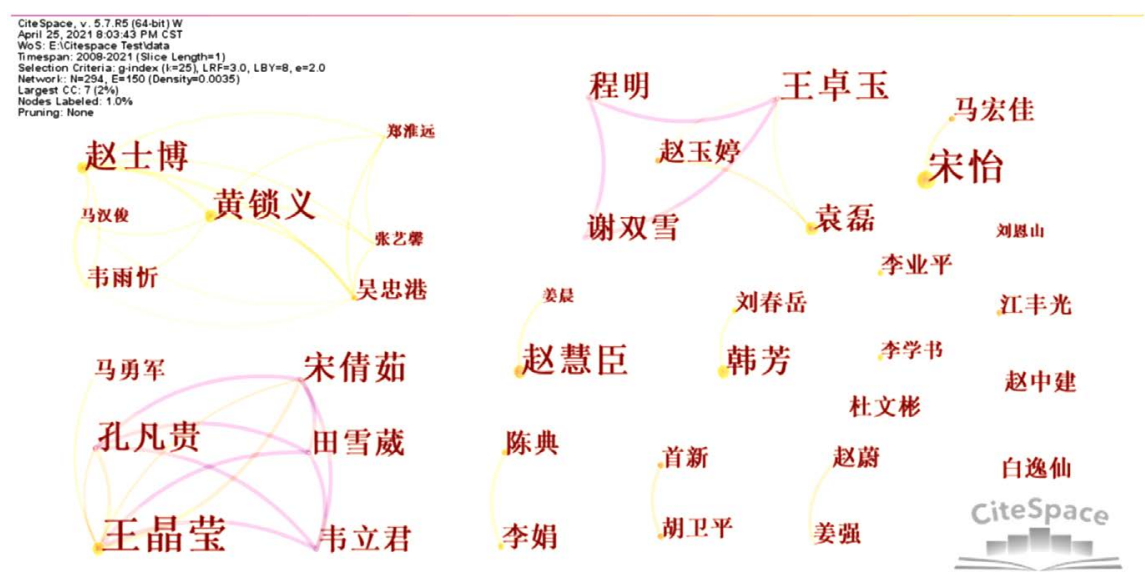

Figure 1. Cooperative atlas of Chinese STEM education authors.

STEM education research has not been formed yet.

In Table 1, the authors in the top 10 are listed. Jingying Wang has the largest number of posts, which shows that Jingying Wang has made a great contribution to the research of STEM education in China. Jingying Wang, whose first STEM education paper appeared in 2008, is the author of China's first STEM education study. The other core authors published between 2010 and 2020, suggesting that the timing of research among core authors varied widely.

\subsubsection{Institutional Analysis}

Through the visual analysis of the Chinese STEM education research institutions, the graph as shown in Figure 2 is drawn. As can be seen from the graph, the main research institutions of STEM education in China are research centers set up by the Ministry of Education or normal colleges and universities. A few teacher colleges and primary and secondary schools have carried out cooperative research, which shows that there is a lack of cooperation between the main research institutions and a lack of connection and communication between teachers colleges and primary and secondary schools. It shows that the research on STEM education in China is relatively closed, and there is still no universal cooperation among research institutions, no cross-institutional and cross-regional research community, and no joint research. The difference of research level between different scientific research institutions is increasing, which is not conducive to the advancement and deepening of research in this field.

China has a large number of institutions that study STEM education. In order to visually display the number of articles published by each institution, Table 2 counts the top 10 institutions in terms of the number of articles published. As can be seen from the table, the East China Normal University is the most prolific publisher and one of the first institutions in China to pay attention to STEM education, with 63 articles published so far. East China Normal University, Beijing Normal University, Northeast Normal University, Shaanxi Normal University and Nanjing Normal University. These five schools are the core institutions of China's STME education research, and the published papers also have a high 


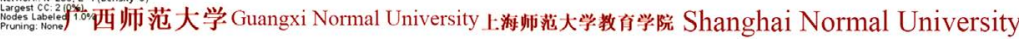

东北师范大学 Dongbei Nurmal University

南京外国语学校 Nanjing Foreign Language School

河南大学教育科学学院 School of Education and science of Henan University 青量大学㐩范学院

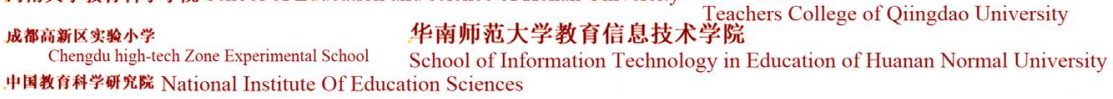

Figure 2. Atlas of China's STEM education research institutions.

Table 1. Chinese STEM education research authors.

\begin{tabular}{|c|c|c|c|}
\hline No. & Name & Research institution & $\begin{array}{c}\text { Document } \\
\text { quantity }\end{array}$ \\
\hline 1 & Jingying Wang & Beijing Normal University & 17 \\
\hline 2 & Huicheng Zhao & Henan University & 13 \\
\hline 3 & Song Yi & Nanjing Xiaozhuang College & 13 \\
\hline 4 & Suoyi Huang & Youjiang Medical College for nationalities & 9 \\
\hline 5 & Zhaoning Ye & Southeast University & 9 \\
\hline 6 & Han Fang & Kashgar University & 7 \\
\hline 7 & Shibo Zhao & Youjiang Medical College for nationalities & 7 \\
\hline 8 & Zhao Wei & Northeast Normal University & 6 \\
\hline 9 & Jiang Qiang & Northeast Normal University & 6 \\
\hline 10 & Weiping $\mathrm{Hu}$ & Shaanxi Normal University & 6 \\
\hline 11 & Li Juan & Hunan Mingzu Vocational College & 6 \\
\hline
\end{tabular}

Table 2. Statistics of Chinese STEM education research institutions.

\begin{tabular}{cccc}
\hline No. & Issuing agency & Institutional attributes & Document quantity \\
\hline 1 & East China Normal University & Double first-rate & 63 \\
2 & Beijing Normal University & Double first-rate & 44 \\
3 & Northeast Normal University & Double first-rate & 32 \\
4 & Shaanxi Normal University & Double first-rate & 30 \\
5 & Nanjing Normal University & Double first-rate & 28 \\
6 & Capital Normal University & Double first-rate & 24 \\
7 & Southwest University & Double first-rate & 19 \\
8 & South China Normal University & Double first-rate & 19 \\
9 & Shanghai Normal University & General institutions & 17 \\
10 & Nanjing Xiaozhuang College & General institutions & 16
\end{tabular}


reference value. In terms of geographical distribution, the main research institutions of the vocational education policy are located in the regions of North China and East China. These areas are supported by high-level universities and colleges, and where the economy is more developed and foreign exchanges are frequent, has access to STEM education materials and cutting edge technology. By contrast, the Northwest China has less research on STEM education due to its geographical location and level of economic development, and the quality of the articles is generally poor, which indicates that there are large regional differences in the level of research on STEM education in China.

\subsection{The Core Field of STEM Education Research in China}

The frequency of keywords in statistics reflects the research hotspot in this field in a certain period. The higher the frequency, the greater the centrality, the higher the heat. The frequency analysis of keywords in the literature data by the CiteSpace software is helpful to understand the research hotspots. Select the node type "Keyword" in CiteSpace, and at the end of the run, you get a graph of the Chinese STEM education research high-frequency Keyword co-word network, as shown in Figure 3. There are 398 keyword nodes, 1094 connections, and a network density of 0.0138 . The frequency of keywords is proportional to the size of the circle, the font of keywords is proportional to the degree of center, and the higher the degree of center is, the more it tends to the center of the graph. The nodes of purple circle are the key nodes (the degree of neutrality is higher than 0.1), and the nodes marked with red circle are emergent nodes. After culling, merging and filtering, the centrality and frequency of the first 15 high-frequency keywords in the cooperative learning study were derived using the CiteSpace software, and the results are shown in Table 3.

Table 3. Key words in Chinese STEM education research.

\begin{tabular}{ccccc}
\hline NO. & Document quantity & Centrality & Year & Keyword \\
\hline 1 & 564 & 1.20 & 2013 & STEM Educatiom \\
2 & 160 & 0.25 & 2008 & STEM \\
3 & 58 & 0.08 & 2015 & STEAM Education \\
4 & 57 & 0.04 & 2015 & Creator Education \\
5 & 57 & 0.09 & 2012 & American \\
6 & 39 & 0.02 & 2008 & Science Education \\
7 & 34 & 0.03 & 2017 & Core literacy \\
8 & 32 & 0.01 & 2017 & STEM Education Philosophy \\
9 & 31 & 0.06 & 2017 & Teaching Mode \\
10 & 30 & 0.03 & 2016 & STEM Courses \\
11 & 26 & 0.02 & 2016 & Instructional Design \\
12 & 28 & 0.00 & 2018 & Meta Analysis \\
13 & 26 & 0.04 & 2013 & Creative Talent \\
14 & 24 & 0.01 & 2016 & Interdisciplinary Learning \\
15 & 22 & 0.04 & 2018 & Primary Science \\
\hline
\end{tabular}




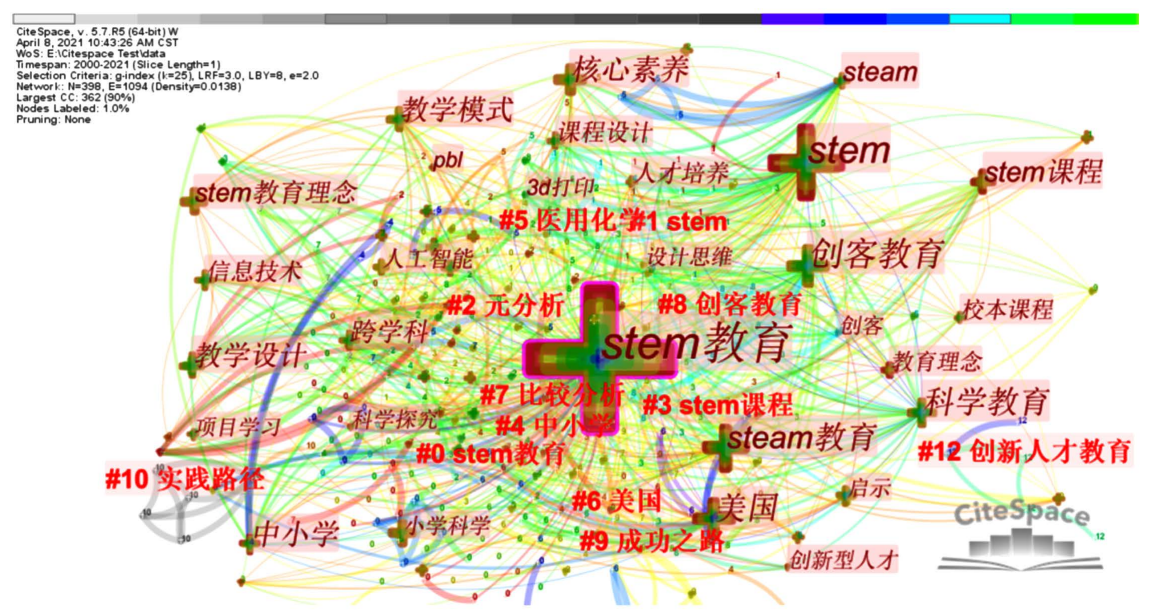

Figure 3. Atlas of Chinese STEM education keywords.

The hot topics of Chinese STEM Education research can be summed up as comparing and drawing lessons from foreign STEM Education, STEM theory analysis, STEM courses and teaching.

1) Draw lessons from STEM education abroad. The high frequency keyword is the United States, appearing 57 times. The United States is the first country to study STEM education, and the related research in China started from the United States. Zhong and Li (2014) have analyzed the emergence and development of the "Transformation equation" in the United States. Through the research on the goal orientation of STEM education, the database of STEM education projects, and the evaluation of STEM education by the non-governmental organization "Transformation equation", it provides reference for China to develop STEM education. Jing and $\mathrm{Hu}$ (2017) summarized the future direction of American STEM Education and the strategies to deal with the challenges in the report by analyzing the joint publication of American Institute and United States Department of Education on STEM 2026: A Vision for Innovation in STEM Education, to provide ideas for the development of STEM education in China. These studies have learned the latest technology of foreign STEM education research and have a strong reference significance to the development of China's STEM education.

2) Analysis of STEM theory. High-frequency keywords include Creator Education, science Education, core literacy, meta-analysis, creativity, interdisciplinary learning. These key words are the research focus of STEM field, and are also theoretical concepts. By analyzing these concepts, we can promote the effective promotion of STEM education in China. One of the most popular research topics is maker education, which is a fusion of information technology, adhering to the "Open innovation, inquiry experience" educational philosophy, to "Create secondary school" as the main way of learning and to train all kinds of innovative talents for the purpose of the new education model (Yang \& Li, 2015). What makes maker education a hot topic in STEM education research is that they have a lot in common, they all need the participation of the society, emphasize the 
real situation problem, and pay attention to the cultivation of the students' comprehensive ability to solve the problem (Yang \& Reng, 2015). As new concepts in China, the relationship and differences between creator education and STEM education have become the focus of related theoretical research.

3) Stem courses and teaching. High frequency keywords include teaching patterns, STEM courses, instructional design, and fundamental science. University teachers and primary and secondary school teachers are the main personnel who study STEM courses and teaching, among them, university teachers mainly study the principles of curriculum and teaching, by analyzing the existing problems of Chinese STEM courses, this paper puts forward improving methods from the aspects of system construction, course standards, course resources, teaching strategies and so on (Dong, 2016). There are also studies from the subject knowledge-centered integration, problem-solving-centered integration and learner-centered integration to put forward the integration of China's STEM curriculum path (Wang, 2018). Primary and secondary school teachers focus on practical research. In primary and secondary schools, based on a specific curriculum, such as primary science curriculum (Zhang et al., 2017), primary school 3D printing curriculum (Zheng, 2016), they design corresponding STEM courses, construct STEM teaching models, and conduct practical teaching, testing the effectiveness of STEM education in practice. These research results enrich the connotation of STEM education, and also verify the possibility and rationality of the development of STEM education in China for the development of indigenous STEM education in China is of great significance.

\subsection{An Analysis of the Research Stages of STEM Education in China}

STEM education is an exotic product for China. The related research of China's STEM education started late. A few scholars started to study STEM education only in 2008. After several years of exploration, STEM education emerged in China around 2013, there is also a growing interest in STEM education. As shown in Figure 4, through the co-occurrence of Chinese STEM education keywords sequence diagram can be seen intuitively the trend of Chinese STEM education research. In 2008, scholar Chen (2008) and others combed the construction measures of American first-class universities and further analyzed the strategy of American STEM education, thus started the theoretical research of Chinese STEM education. From 2008 to 2010, China's STEM education research was in its infancy, with no more than 10 papers published and few high-quality studies. Since 2010, more and more research has been done on STEM education in China, and the research direction is to sort out and interpret the policies and development of STEM education abroad. In 2015, China's Ministry of Education issued the Guiding opinions on comprehensively and deeply promoting education informatization during the 13th Five Year Plan Period. In 2016, China's Ministry of education promulgated The 13th five year plan of educational informatization. These two documents plan the development of China's future 


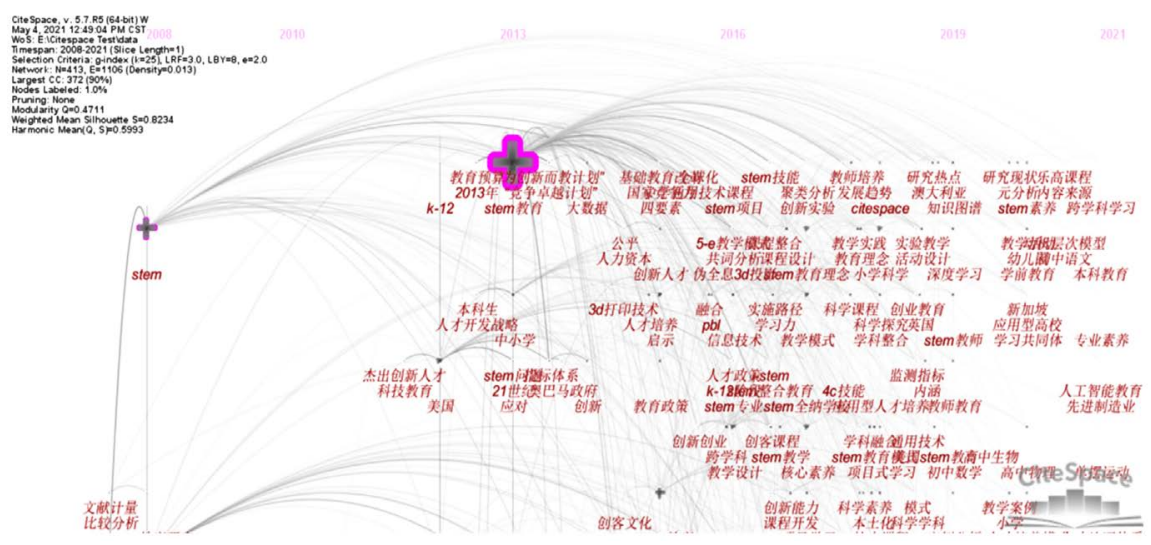

Figure 4. Timeline of Chinese STEM education keywords

STEM education, so the research of STEM education has become a hot spot of domestic education research after 2015.

Based on this, we can roughly divide the research of STEM education in China into three stages. Phase One, preliminary exploration. From 2008 to 2010, the amount of papers and researchers are relatively small, the research is in the initial state, and the research content is mostly the concept of STEM education interpretation and popular science. Phase Two, rapid development. From 2010 to 2015, domestic scholars such as Zhongjian Zhao, Huicheng Zhao and Shengquan $\mathrm{Yu}$ have done a lot of research on STEM education. The research contents include the interpretation of foreign STEM education and the theoretical research on the localization of Chinese STEM education. The third stage is to deepen the research period. From 2015 to 2021, the number of 2021 and researchers has fluctuated greatly, the research topics have been deepened, the research fields have been expanded and the practice models have been enriched, and the related research has gradually been attached importance by the government and related researchers.

\subsection{Analysis on the Frontier Problems of STEM Education Research in China}

Select Citation/Frequency Burst in CiteSpace to get the highlighting keyword. Figure 5 shows nine emergent key words in Chinese STEM education research, as well as the intensity and start-stop time of the emergent key words, the importance of which is determined by the emergent value. Through the analysis of emergent words, we will get the research frontier of the research field. Among them, the four key words of science education, USA, Topic modeling and STEM education research emerged for the longest time, indicating that these topics have been fully developed in China's STEM education research. The key words of maker education, maker space and maker are the research hotspots in recent years. The emergent time is from 2015 to 2017, which indicates that these topics are the new products after the development of STEM education becomes mature. 
Top 9 Keywords with the Strongest Citation Bursts

\begin{tabular}{|c|c|c|c|c|c|}
\hline Keywords & Year & Strength & Begin & End & $2008-2021$ \\
\hline Science Education & 2008 & 6.52 & 2008 & 2016 & \\
\hline American & 2008 & 4.88 & 2008 & 2016 & \\
\hline Topic modeling & 2008 & 4.88 & 2008 & 2016 & \\
\hline STEM Educational Research & 2008 & 4.61 & 2008 & 2016 & \\
\hline Lierature metrology & 2008 & 3.88 & 2008 & 2013 & \\
\hline Comparative analysis & 2008 & 3.88 & 2008 & 2013 & \\
\hline Maker Education & 2008 & 5.44 & 2015 & 2017 & \\
\hline Maker Space & 2008 & 3.9 & 2015 & 2017 & \\
\hline Make & 2008 & 3 & 2015 & 2017 & \\
\hline
\end{tabular}

Figure 5. Key words emerging in Chinese STEM education research.

Looking at the keyword pop-up graph, combined with the analysis of the previous section, we can predict the general direction of China's STEM education research in the future. First, science education is still a hot issue in STEM education research, with an emergent value of 6.52 . Science education has always been the focus of primary and secondary education. After the introduction of STEM education into China, as a new research perspective, it provides a new paradigm for science education and opens up a broader and more integrated vision (Wang, 2015). According to the latest literature, the five major fields of research in international science education are all centered on STEM, and China is constantly exploring a new type of science education system (Song, 2018). Second, the keyword "United States" has an emergent value of 4.88, indicating that future research is still part of the study of the development of STEM education in the United States and other countries by looking at the latest developments in STEM education in developed countries, it provides the reference for the related research in China. Third, creator education may become the mainstream trend of STEM education research in China. With the rapid development of the Internet and information technology, the Maker education is a kind of innovation education upsurge, which has developed in recent years with the rise of the Maker Movement and the spread of the Maker culture. Its essence is a new educational paradigm, which is the integration of digital technology and education. It will redefine the integrated practical curriculum and information technology curriculum in primary and secondary schools (Tian et al., 2021). Under the background of the great development of information technology, the integration of STEM education and new educational technology will become a major direction of the future development of China's STEM education.

\subsection{Summary}

Based on the analysis of the current situation of STEM education research in China, this paper summarizes the core authors and core research institutions of STEM education research in China. This paper finds out the hot issues in the 
research of STEM education in China, forecasts the direction of the research of STEM education in China in the future, and provides reference for the related research in the future.

\section{Conclusion}

CiteSpace can analyze the potential knowledge contained in the literature and visualize the structure, regularity and distribution of scientific knowledge based on scientometrics. This paper presents a visual analysis of the literature on STEM education research in China with the help of CiteSpace, and explains the results of the analysis in detail.

First, based on the analysis of the core authors and research institutions of China's STEM education research, it is found that the core author group of China's STEM education research has not yet formed, and there is no universal cooperation among the authors and research institutions, moreover, the difference of research level between different research institutions is increasing, which is not conducive to the advancement and deepening of research in this field.

Secondly, through the analysis of the hot issues of China's STEM education research, it is found that the core areas of China's STEM education research mainly include the comparison and reference of STEM education abroad, STEM theory analysis, STEM courses and teaching, relevant research has formed a relatively mature system.

Thirdly, through the analysis of the research stages and frontier issues of China's STEM education, the research trends of China's STEM education are divided into the initial exploration period (2008-2010), the fast development period (2010-2015) and the deepening research period (2015-2021), which are the three stages of the research of China's STEM education. In the future, science education, STEM education of foreign countries, STEM courses and teaching and other practical research will become the focus of China's STEM education research.

\section{Author Contributions}

Chendong Zhou designed the research at the beginning and prepared the first draft of the paper. As a corresponding author, Yuanyuan Li analyzed the data and participated in the revision of the paper. All authors approved the final draft.

\section{Conflicts of Interest}

The authors declare no conflicts of interest regarding the publication of this paper.

\section{References}

Chen, C. (2008). The World-Class University Strategy of the United States and Its Enlightenment. Research on Higher Education in China, 11, 48-50. 
Chen, P., \& Tian, Y. (2019). Research and Enlightenment of Stem Education Innovation Curriculum Based on Design Thinking-Taking D Loft Stem Curriculum of Stanford University as an Example. China Educational Technology, 8, 82-90.

Dong, Z. H. (2016). On the Difficulties and Countermeasures of Implementing STEM Curriculum in Primary and Middle Schools in China. Global Education Outlook, 35, 17-25. https://kns.cnki.net/kcms/detail/detail.aspx?dbcode=CJFD\&dbname=CJFDLAST2017 \&filename $=$ WGJN201612003\&v=b11JIakeXjcK7xlPkPnNzjXy5k9Zg\%25mmd2FaDd1S c\% $25 \mathrm{mmd} 2 \mathrm{FHQ} 2 \mathrm{hbFFcl} \% 25 \mathrm{mmd} 2 \mathrm{FbzQOaFACG0WbfF} 4 \mathrm{~s}$

Han, X. (2018). The Development and Trend of Cooperative Learning Research in China in the Past 40 Years of Reform and Opening-Up: A Bibliometrics Analysis Based on CITESPACE Tools. Contemporary Educational Science, 4, 76-83.

Jing, H., \& Hu, Y. Y. (2017). Leading the Future of Education with Innovation of STEM Education-Interpretation and Enlightenment of the Report STEM 2026: Innovation Vision of STEM Education in the United States. Journal of Distance Education, 1, 17-25.

Li, J., \& Chen, C. M. (2016). CiteSpace: Technology Text Mining and Visualization. Beijing: Capital University of Economics and Business.

Price, D., \& Zhang, J. Y. (1984). LOTCA's Law and Price's Law. Science of Science and Management of Science and Technology, 9, 17-22.

https://d.wanfangdata.com.cn/periodical/ChlQZXJpb2RpY2FsQ0hJTmV3UzIwMjEwN TIxEg5RSzAwMDAwNDMxODU5MhoId20xdWN1eDI\%3D

Qin, J. R., \& Fu, G. S. (2017). Stem Education: Interdisciplinary Education Based on Real Problem Scenarios. China Educational Technology, 4, 67-74.

Song, Y. (2018). Science Teaching in the Perspective of STEM Literacy: Critical Thinking and Reconstruction. Modern Educational Science, 8, 96-100.

Tian, X. M., Wang, J. Y., \& Song, Q. R. (2021). Stem-Oriented Prospect of Contemporary International Science Education Research-Text Mining Based on NARST 2020 Conference. Modern Distance Education, 1, 78-88.

Wang, L. (2018). From "Division" to "Integration": The Predicament and Innovation Path of the Integration of STEM Courses. Shanghai Education and Scientific Research, 12, 71-75.

Wang, X. Q. (2015). Research on the Model of Innovator Education for STEM Education. Audio-Visual Education in China, 8, 36-41.

Yang, X. M., \& Li, Y. H. (2015). The Value Potential of Maker Education and Its Controversy. Research on Modern Distance Education, 2, 23-34.

Yang, X. Z., \& Reng, Y. Q. (2015). STEM Education and Maker Education in the Digital Age. Open Education Research, 21, 35-40.

Ye, Z. N., \& Zhu, L. N. (2016). How to Realize the Integration of All Fields of "Integrated STEM" Course-Taking the Elevator of American STEM Course Unit as an Example. People's Education, 12, 58-63.

https://kns.cnki.net/kcms/detail/detail.aspx?dbcode=CJFD\&dbname=CJFDLAST2016 \&filename $=$ RMJY201612022\&v=lot1uuvzOiPGTiSIE3TYV ceEJ4SQbH1aMzaFiRDLcr9 3Il\%25mmd2BaJKe77RgG06LPdGlB

Yu, S. Q., \& Hu, X. (2015). Stem Education Concept and Interdisciplinary Integration Mode. Research on Open Education, 21, 13-22.

Zhang, Q., Zhao, Y. P., \& He, L. (2017). Design and Practice of Interdisciplinary Teaching Based on STEM. Research on Modern Distance Education, 6, 75-84. 
Zhao, Z. J. (2015). Progress of Stem Education Policy in the United States. Shanghai: Shanghai Science and Technology Education Press.

Zheng, X. (2016). Research on Course Design and Teaching Practice of 3D Printing in Primary School Based on Steam. Audio-Visual Education in China, 6, 75-84.

Zhong, B. C., \& Li, F. Z. (2014). The Function of "Transformation Equation" in the Transformation of American STEM Education and Its Enlightenment. Audio-Visual Education in China, 4, 18-24+86.

Zhu, Z. T., \& Lei, Y. H. (2017). National Policy Analysis and Practice Mode of Stem Education. E-Education Research, 39, 75-85. 